\title{
ASTHMA
}

\section{Sustained reduction in bronchial hyperresponsiveness with inhaled fluticasone propionate within three days in mild asthma: time course after onset and cessation of treatment}

\author{
A R A Soviiärvi, T Haahtela, H J Ekroos, A Lindqvist, A Saarinen, T Poussa, L A Laitinen
}

Thorax 2003;58:500-504

See end of article for authors' affiliations

Correspondence to: Professor A R A Sovijärvi, Laboratory of Clinical Physiology, Meilahti Hospital, Helsinki University Hospital, P O Box 340, FIN-00029 HUS, Helsinki, Finland; anssi.sovijarvi@hus.fi

Revised version received 2 December 2002 Accepted for publication 18 February 2003
Background: Bronchial hyperresponsiveness (BHR) is characteristic of asthmatic airways, is induced by airway inflammation, and is reduced by inhaled corticosteroids (ICS). The time course for the onset and cessation of the effect of ICS on BHR is unclear. The effect of inhaled fluticasone propionate (FP) on BHR in patients with mild persistent asthma was assessed using time intervals of hours, days and weeks.

Methods: Twenty six asthmatic patients aged 21-59 years were selected for this randomised, double blind, parallel group study. The effect of $250 \mu \mathrm{g}$ inhaled FP (MDI) administered twice daily was compared with that of placebo on BHR assessed using a dosimetric histamine challenge method. The dose of histamine inducing a decrease in forced expiratory volume in 1 second $\left(\mathrm{FEV}_{1}\right)$ by $15 \%\left(\mathrm{PD}_{15} \mathrm{FEV}_{1}\right)$ was measured before and 6, 12, 24 and 72 hours, and 2, 4 and 6 weeks after starting treatment, and 48 hours, 1 week and 2 weeks after cessation of treatment. Doubling doses of changes in $\mathrm{PD}_{15} \mathrm{FEV}_{1}$ were calculated and area under the curve $(A \cup C)$ statistics were used to summarise the information from individual response curves.

Results: The increase in $\mathrm{PD}_{15} \mathrm{FEV}$, from baseline was greater in the FP group than in the placebo group; the difference achieved significance within 72 hours and remained significant until the end of treatment. In the FP group PD ${ }_{15} \mathrm{FEV}_{1}$ was 1.85-2.07 doubling doses above baseline between 72 hours and 6 weeks after starting treatment. BHR increased significantly within 2 weeks after cessation of FP treatment.

Conclusions: A sustained reduction in BHR to histamine in patients with mild asthma was achieved within 3 days of starting treatment with FP at a daily dose of $500 \mathrm{\mu g}$. The effect tapered within 2 weeks of cessation of treatment.
$\mathrm{B}$ ronchial asthma is characterised by increased numbers of eosinophils, neutrophils and lymphocytes in the airways, bronchial hyperresponsiveness (BHR), and reversible airway obstruction. Inhaled corticosteroids (ICS) may reduce BHR and more direct markers of airway inflammation such as sputum eosinophils and exhaled nitric oxide, but their mutual associations are not straightforward. ${ }^{1-5}$

A significant decrease in BHR has been reported with high doses of ICS in corticosteroid naive asthmatics within 2-8 weeks of starting treatment in many studies. ${ }^{6}$ Even the first dose of ICS has been shown to reduce BHR both in adults ${ }^{7}$ and in children. ${ }^{9}$ The dose dependent effect of ICS on BHR has also been reported previously. ${ }^{10}$ After cessation of ICS, BHR has reverted to baseline values within days or weeks, depending on the dose and duration of treatment. ${ }^{11}{ }^{12}$ However, only limited data are available on the time course in hours, days, and weeks of the steroid effect on BHR after the onset or cessation of treatment. Such information would be valuable, especially in mild asthma where repeated short treatment periods of ICS are often used for early symptoms.

In this 8 week study we evaluated the rate, speed, and consistency of the effect of a regular dose of inhaled fluticasone propionate (FP) on BHR to inhaled histamine and lung function in patients with mild asthma who were not using inhaled steroids. During the 6 week treatment period short evaluation intervals starting from 6 hours were used. The time course of changes in BHR and lung function was followed for 2 weeks after cessation of treatment, and changes in symptoms were also followed.

\section{METHODS}

\section{Subjects}

The criteria for inclusion in the study were:

(1) age at least 18 years;

(2) asthma diagnosis based on one or more of the following criteria assessed before the 1-2 week run in period: improvement by at least $15 \%$ in forced expiratory volume in the first second $\left(\mathrm{FEV}_{1}\right)$ or peak expiratory flow (PEF) in bronchodilatation tests, diurnal variation in PEF of at least $20 \%$ calculated according to ERS guidelines, ${ }^{13}$ or exercise induced fall in PEF or $\mathrm{FEV}_{1}$ of at least $15 \%$ from baseline;

(3) $\mathrm{FEV}_{1}$ at baseline at least $65 \%$ of predicted $^{14}$;

(4) bronchial responsiveness to inhaled histamine determined as the provocative dose inducing a $15 \%$ fall in $\mathrm{FEV}_{1}\left(\mathrm{PD}_{15} \mathrm{FEV}_{1}\right)$ of $0.6 \mathrm{mg}$ or less ${ }^{15}$ during the run in period;

(5) written informed consent.

The criteria for exclusion were:

(1) seasonal or unstable asthma;

(2) respiratory tract infection or exacerbation of asthma during the 4 weeks before entry into the study;

(3) current smoking or cessation of smoking within the year preceding the study;

(4) history of any pulmonary disease other than asthma;

(5) use of inhaled or oral steroids, inhaled chromones, or leukotriene antagonists during the 2 months before the study; 
Table 1 Patient characteristics and baseline values of $\mathrm{PD}_{15} \mathrm{FEV}_{1}, \mathrm{FEV}_{1}$, daily PEF, symptom scores, and use of rescue medication in the two treatment groups

\begin{tabular}{|c|c|c|}
\hline & $\begin{array}{l}\text { Fluticasone propionate } \\
(n=13)\end{array}$ & $\begin{array}{l}\text { Placebo } \\
(n=13)\end{array}$ \\
\hline Height $(\mathrm{cm})$ & $169(157-189)$ & 174 (160-194) \\
\hline Weight (kg) & $67.3(45-88)$ & $78.4(48-113)$ \\
\hline Age (years) & $34.5(21-53)$ & $38.5(21-59)$ \\
\hline$M / F$ & $4 / 9$ & $7 / 6$ \\
\hline Smoking (never/ex-smokers) & $9 / 4$ & $9 / 4$ \\
\hline $\begin{array}{l}\text { Mean duration of reversible airway } \\
\text { obstruction (years) }\end{array}$ & $12.9(0.1-37)$ & $8.0(0.1-33)$ \\
\hline No of atopics & 9 & 10 \\
\hline $\mathrm{FEV}_{1}(\% \text { pred })^{* * *}$ & $79.3(70-88)$ & $84.3(69-100)$ \\
\hline $\mathrm{PD}_{15} \mathrm{FEV}_{1}(\mathrm{mg})^{*}$ & $0.122(0.016-0.498)$ & $0.233(0.006-1.10)$ \\
\hline \multicolumn{3}{|l|}{ Mean daily PEF (\% pred)** } \\
\hline Morning & 81 (64-99) & $92(71-112) \dagger$ \\
\hline Evening & 83 (63-99) & $95(72-116) \dagger$ \\
\hline \multicolumn{3}{|l|}{ Mean symptom score } \\
\hline Daytime (0-5) & 0.12 & 0.27 \\
\hline Night time $(0-4)$ & 0.46 & 0.51 \\
\hline $\begin{array}{l}\text { Mean weekly sum of doses of rescue } \\
\text { medication }\end{array}$ & 3.8 & 4.6 \\
\hline \multicolumn{3}{|c|}{$\begin{array}{l}\text { Continuous variables are expressed as mean (range) values. } \\
{ }^{*} \text { Geometric mean. } \\
* * \text { Reference values: Nunn and Gregg. } \\
* \star * \text { Reference values: Vilianen et al. }{ }^{14} \\
\dagger p<0.02 \text { (comparison between treatment groups). }\end{array}$} \\
\hline
\end{tabular}

Table 2 Mean $(95 \% \mathrm{Cl})$ changes in $\mathrm{PD}_{15} \mathrm{FEV}_{1}$ values in doubling doses (DD) compared with baseline in fluticasone propionate (FP) and placebo groups and mean $(95 \% \mathrm{CI})$ differences between groups

\begin{tabular}{|c|c|c|c|}
\hline Time from treatment onset & Fluticasone $(n=13)$ & Placebo $(n=13)$ & Difference (FP v placebo) \\
\hline \multicolumn{4}{|l|}{ Treatment $v$ baseline } \\
\hline 6 hours & $0.58(-0.07$ to 1.22$)$ & $0.63(-0.17$ to 1.43$)$ & $-0.06(-1.03$ to 0.92$)$ \\
\hline 12 hours & $1.26(0.70$ to 1.82$)$ & $0.43(-0.26$ to 1.12$)$ & $0.83(-0.01$ to 1.67$)$ \\
\hline 24 hours & 1.75 (1.08 to 2.43$)$ & $1.03(0.47 \text { to } 1.60)^{\prime}$ & $0.72(-0.12$ to 1.56$)$ \\
\hline 72 hours & 1.98 (1.33 to 2.63$)$ & $0.79(-0.11$ to 1.70$)$ & $1.19(0.13$ to 2.25$)$ \\
\hline 2 weeks & 1.92 (1.07 to 2.77$)$ & $0.59(-0.16$ to 1.34$)$ & $1.33(0.26$ to 2.40$)$ \\
\hline 4 weeks & $1.85(0.88$ to 2.82$)$ & $0.58(-0.15$ to 1.31$)$ & 1.27 (0.12 to 2.42$)$ \\
\hline 6 weeks & 2.07 (1.30 to 2.83$)$ & $0.09(-0.64$ to 0.81$)$ & $1.98(0.98$ to 2.98$)$ \\
\hline \multicolumn{4}{|l|}{ Post-treatment $v$ baseline } \\
\hline 48 hours & $1.47(0.32$ to 2.61$)$ & $0.66(-0.12$ to 1.45$)$ & 0.81 (-0.48 to 2.09$)$ \\
\hline 1 week & 1.15 (0.01 to 2.29 ) & $0.11 \quad(-0.74$ to 0.96$)$ & $1.04(-0.29$ to 2.3$)$ \\
\hline 2 weeks & $0.85(-0.57$ to 2.27$)$ & $0.26(-0.37$ to 0.89$)$ & $0.59(-0.82$ to 2.00$)$ \\
\hline \multicolumn{4}{|l|}{ Post-treatment $v 6$ weeks } \\
\hline 48 hours & $-0.40(-1.00$ to 0.20$)$ & $0.43(-0.04$ to 0.90$)$ & $(-0.83(-1.54$ to -0.12$)$ \\
\hline 1 week & -0.72 (-1.34 to -0.09$)$ & $-0.12(-0.72$ to 0.48$)$ & $-0.60(-1.41$ to 0.22$)$ \\
\hline 2 weeks & $-1.02(-2.19$ to 0.16$)$ & $0.03(-0.58$ to 0.63$)$ & $-1.04(-2.25$ to 0.17$)$ \\
\hline
\end{tabular}

(6) use of antihistamines within 2 weeks and long acting $\beta_{2}$ agonists within 4 weeks before entry into the study;

(7) pregnancy or breast feeding;

(8) any severe chronic disease;

(9) alcohol or drug abuse.

Twenty six outpatients aged 21-59 years were enrolled into the study and randomised to receive either FP $(n=13)$ or placebo $(n=13)$. Characteristics of the groups are given in table 1 . The mean baseline $\mathrm{FEV}_{1}$ of all the patients was $81.8 \%$ predicted (range 69-100). ${ }^{14}$ At baseline they showed at least slight BHR to inhaled histamine diphosphate; $\mathrm{PD}_{15} \mathrm{FEV}_{1}$ varied between 0.006 and $1.1 \mathrm{mg}$. The duration of asthma ranged between 0.1 and 37 years (mean 10.5).

According to skin prick tests made with 11 common inhalant allergens (Soluprick SQ, 10 HEP, ALK, Denmark), 19 of the 26 patients were atopic (at least one allergen gave a weal reaction of $3 \mathrm{~mm}$ or more when control solutions gave expected results).

The treatment groups were similar in terms of age, sex, smoking history, duration of asthma, atopy, $\mathrm{FEV}_{1}, \mathrm{PD}_{15} \mathrm{FEV}_{1}$, symptom score, and use of rescue medication. The morning and evening PEF during the week before randomisation were slightly higher in the placebo group $(\mathrm{p}=0.02$, table 1$)$.

\section{Study design}

A randomised, placebo controlled, double blind, parallel group study design was used. During the run in period of $1-2$ weeks the patients continued to take their usual asthma medication and daily recorded the asthma symptom score (ranging in the day between 0 and 5 and at night between 0 and 4), use of salbutamol (Ventolin MDI, $100 \mu \mathrm{g}$, Glaxo Wellcome, Germany) and morning and evening PEF values (best of three) using a mini-Wright peak flow meter (Clement Clarke International, Essex, UK).

During the 6 week treatment period the patients inhaled either FP $250 \mu \mathrm{g}$ MDI (Glaxo Wellcome, Germany) or placebo twice daily at 12 hour intervals by using a spacer (Volumatic, Glaxo Wellcome, Germany). The patients were allowed to use inhaled salbutamol as needed but not within 12 hours before measurements of $\mathrm{PD}_{15} \mathrm{FEV}_{1}$ and $\mathrm{FEV}_{1}$. No other asthma drugs were permitted. 
Table 3 AUC of doubling doses (DD) summed over 6-72 hours (short term effect) and over 2-6 weeks (long term effect) after start of treatment

\begin{tabular}{|c|c|c|c|c|}
\hline Treatment effect & Fluticasone $(n=13)$ & Placebo $(n=13)$ & Difference (FP $\vee$ placebo) & $p$ value* \\
\hline $\begin{array}{l}\text { Short term effect: standardised } \\
\text { AUC (6-72 h) }\end{array}$ & 1.60 (1.03 to 2.16$)$ & $0.80(0.19$ to 1.41$)$ & $0.79(0.01$ to 1.58$)$ & 0.048 \\
\hline $\begin{array}{l}\text { Long term effect: standardised } \\
\text { AUC ( } 2-6 \text { weeks) }\end{array}$ & 1.92 (1.08 to 2.76$)$ & $0.46(-0.22$ to 1.14$)$ & $1.46(0.44$ to 2.48$)$ & 0.007 \\
\hline $\begin{array}{l}\text { Post-treatment } v \text { baseline: } \\
\text { standardised AUC } \\
\text { ( } 48 \text { h-2 weeks) }\end{array}$ & $1.13(0.00$ to 2.26$)$ & $0.27(-0.41$ to 0.95$)$ & $0.86(-0.35$ to 2.07$)$ & 0.155 \\
\hline $\begin{array}{l}\text { Post-treatment } v 6 \text { weeks: } \\
\text { standardised AUC } \\
\text { ( } 48 \text { h-2 weeks) }\end{array}$ & $-0.66(-1.26$ to -0.07$)$ & $0.06(-0.33$ to 0.45$)$ & $-0.72(-1.38$ to -0.07$)$ & 0.033 \\
\hline
\end{tabular}

Post-treatment changes (48 hours, 1 week and 2 weeks) are compared with those at baseline and at 6 weeks (last dose). Standardised AUC values (AUC related to time period) and their comparisons between the groups are given as means $(95 \%$ confidence intervals).

${ }^{*} t$ test for independent groups.

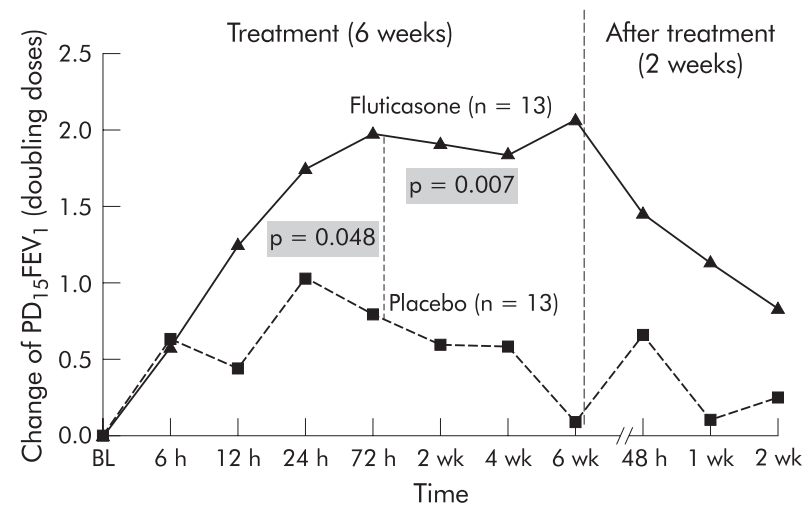

Figure 1 Time course of the effect of inhaled fluticasone propionate (FP) $250 \mu \mathrm{g}$ twice daily $(n=13)$ or placebo $(n=13)$ on bronchial hyperresponsiveness (BHR) in patients with mild asthma. Changes in $\mathrm{BHR}$ are presented as mean changes in $\mathrm{PD}_{15} \mathrm{FEV}$, for histamine expressed as doubling dose units compared with baseline $\mathrm{PD}_{15} \mathrm{FEV}$, values. Patients were treated with FP for 6 weeks and followed for 2 weeks after cessation of treatment. $p$ values indicate significant differences between the FP and placebo groups from 6 to 72 hours $(p=0.048)$ and from 2 to 6 weeks $(p=0.007)$ (area under the curve analysis). $\mathrm{BL}=$ baseline.

A spirometric test and the bronchial challenge with inhaled histamine were performed at baseline, at 6, 12, 24 and 72 hours, and at 2, 4 and 6 weeks after the first dose of the treatment regimen. After cessation of treatment (after the last dose) the measurements were repeated at 48 hours and at 1 and 2 weeks (follow up). The study drugs were administered immediately after the measurements of $\mathrm{FEV}_{1}$ and BHR at baseline and at 12, 24 and 72 hours during the treatment period. During the last treatment week and the second week after treatment cessation the patients daily recorded symptoms and PEF as during the run in period.

The study protocol was approved by the ethics committee of the Department of Medicine of Helsinki University Hospital and subjects gave written consent before taking part.

\section{Measurement of lung function and BHR}

The patients were not allowed to drink coffee, tea or coke, or to partake of heavy exercise within 2 hours or alcohol-containing beverages within 36 hours before the spirometric and histamine challenge tests. Antihistamines were forbidden for 5 days and antitussive drugs for 3 days before the histamine tests. Before the start of the lung function tests the patients rested in the laboratory for at least 15 minutes.

$\mathrm{FEV}_{1}$ was measured with a flow-volume spirometer (Vitalograph alpha, Vitalograph, Ireland) according to the American Thoracic Society statement on standardisation of spirometry. ${ }^{16}$ Spirometric tests always preceded the bronchial challenge tests.

Bronchial challenge tests were performed using a dosimetric method with controlled tidal breathing, described in detail elsewhere. ${ }^{15}$ An automatic inhalation synchronised jet nebuliser (Spira Elektro 2, Respiratory Care Center, Hämeenlinna, Finland) was used for administration of buffered histamine diphosphate in a four step non-cumulative dosage scheme $(0.025,0.1,0.4$, and $1.6 \mathrm{mg})$. In cases where $\mathrm{FEV}_{1}$ did not decrease from baseline by $15 \%$ or more after the highest dose, an extra dose of $3.2 \mathrm{mg}$ was given. The histamine response was measured by using $\mathrm{FEV}_{1}$ determinations with a wedge spirometer (Vitalograph PF 2, Vitalograph, UK). When FEV decreased from baseline by $15 \%$ or more after any dose, further administration of histamine was discontinued. After the last histamine dose, patients inhaled two puffs of a very short acting $\beta_{2}$ agonist, rimiterol $400 \mu \mathrm{g}$ (Pulmadil, 3M-Riker) using a Volumatic spacer to resolve bronchoconstriction.

$\mathrm{PD}_{15} \mathrm{FEV}_{1}$ values were calculated from logarithmically transformed histamine doses using linear interpolation.

\section{Statistical analyses}

Sample size calculations were based on the primary variable $\mathrm{PD}_{15} \mathrm{FEV}_{1}$. In the groups of 13 patients a mean difference of 1.0 dose step (SD 0.84 ) was estimated to have an $80 \%$ probability of being detected with a $t$ test at a significance level of $5 \%$. The changes in $\mathrm{PD}_{15} \mathrm{FEV}_{1}$ from baseline were calculated using the doubling dose (DD) technique. The within-group changes in doubling dose units and the comparisons between the groups were given as means with $95 \%$ confidence intervals at each time point. The repeated DD measurements were summed using the area under the curve (AUC) method with linear trapezoidal application. AUC analysis was split into three successive time segments. The measurements from 6 to 72 hours were summed to assess the short term effect of FP treatment and the subsequent measurements from 2 to 6 weeks to assess the long term effect. In addition, after cessation of treatment the changes were summed using the AUC method; comparisons were made both with baseline and with the last dose of FP or placebo.

All AUC values were divided by the total time of each AUC segment to get an average level of doubling doses over the time segment (standardised AUC). The standardised AUC values in the treatment groups and the differences between the groups were calculated as means with $95 \%$ confidence interval. A $t$ test for independent samples was used to compare the standardised AUC values between the treatment groups.

Changes in $\mathrm{FEV}_{1}$ (percentage predicted) from baseline during the trial were also calculated using standardised AUC values over the same time segments as for DD units. Changes in morning and evening PEF (percentage predicted) from baseline to the last week of treatment were analysed using a $t$ test for independent samples. The changes in symptom scores 
and the use of rescue medication were analysed using the Mann-Whitney U test.

\section{RESULTS}

At baseline the geometric mean $\mathrm{PD}_{15} \mathrm{FEV}_{1}$ in the FP group was $0.122 \mathrm{mg}$ and in the placebo group $0.233 \mathrm{mg}$ (difference not significant, table 1). Changes in $\mathrm{PD}_{15} \mathrm{FEV}_{1}$ from baseline in the FP and placebo groups and the differences between the groups are presented in doubling dose units (mean, 95\% CI) in table 2 , and the results from the AUC analysis are shown in table 3. Mean changes in $\mathrm{PD}_{15} \mathrm{FEV}_{1}$ during and after the treatment periods in both patient groups are shown in fig 1 .

The increase in $\mathrm{PD}_{15} \mathrm{FEV}_{1}$ from baseline was greater in the FP group than in the placebo group. The short term difference between the treatment groups in 6-72 hours was significant $(p=0.048)$, and the effect was sustained until the end of the treatment period ( $2-6$ weeks, $p=0.007$; fig 1 , table 3 ). In the FP group the $\mathrm{PD}_{15} \mathrm{FEV}_{1}$ between 72 hours and 6 weeks after the start of treatment was 1.85-2.07 doubling doses above the baseline level and the difference between the treatments during that period was 1.19-1.98 doubling doses (table 2). At the end of the 6 week treatment period the geometric mean $\mathrm{PD}_{15} \mathrm{FEV}_{1}$ in the FP group was $0.510 \mathrm{mg}$ (range 0.061-2.369) and in the placebo group $0.248 \mathrm{mg}$ (range 0.003-1.912).

After cessation of treatment the effect of FP on BHR diminished significantly within 2 weeks ( $p=0.003$; fig 1 , tables 2 and 3 ). At the end of the 2 week follow up period $\mathrm{PD}_{15} \mathrm{FEV}_{1}$ had returned to near pretreatment levels in the FP group $(0.85$ doubling doses above baseline). The geometric mean $\mathrm{PD}_{15} \mathrm{FEV}_{1}$ at the end of the 2 week follow up period was $0.294 \mathrm{mg}$ (range $0.042-1.925$ ) in the FP group and $0.280 \mathrm{mg}$ (range 0.0141.827 ) in the placebo group.

$\mathrm{FEV}_{1}$ (percentage predicted) did not increase significantly from baseline in the FP group compared with the placebo group within 72 hours (mean change $2.9 \% v 0.3 \%, \mathrm{p}=0.084$ ), but the long term effect was significant (mean difference from 2 to 6 weeks $3.8 \% v-0.3 \%, \mathrm{p}=0.028)$.

No statistically significant differences were seen between the treatment groups in the PEF values recorded at home. Morning and evening PEF values increased 2.4\% and 2.5\%, respectively, in the FP group and there was a corresponding decrease of $0.4 \%$ and $0.5 \%$ in the placebo group. Symptom scores or the use of rescue medication between the groups were not significantly different during or after treatment.

\section{DISCUSSION}

We studied asthmatic patients with near normal lung function but increased BHR to histamine whose respiratory symptoms were controlled with inhaled $\beta_{2}$ agonists only. They had been without inhaled corticosteroids for at least 2 months before entry to the study, so they could be regarded as steroid naive. However, the duration of the disease in most of the patients had been more than 2 years. Although the disease was persistent, its severity was mild based on low symptom scores, only slightly (if any) reduced lung function, and limited use of rescue medication.

The hourly or daily changes in BHR after the start or cessation of treatment with ICS have not previously been studied. No data are available on how rapidly a sustained reduction in BHR can be obtained after starting ICS treatment. In the present study the BHR in terms of $\mathrm{PD}_{15} \mathrm{FEV}_{1}$ for histamine was reduced and reached a plateau within 72 hours of starting treatment. The maximal effect was obtained within 6 weeks. A significant improvement was also found in $\mathrm{FEV}_{1}$ within 6 weeks of commencing FP treatment. Most of the treatment effect on BHR disappeared within 2 weeks of cessation of treatment.

The moderate dose of FP used in this study $(250 \mu \mathrm{g}$ twice daily) is common in clinical practice. A recent meta-analysis by van Grunsven et al ${ }^{6}$ in steroid naive asthmatics concluded that $1000 \mu \mathrm{g}$ budesonide or the equivalent reduced BHR on average by 1.16 doubling doses compared with placebo $(95 \%$ CI 0.76 to 1.57 ) within $2-8$ weeks of treatment. No clear relationship was found between the dose of inhaled steroid and the decrease in BHR. In the present study the effect of FP on BHR was 1.98 doubling doses at 3 days and 2.07 doubling doses at 6 weeks compared with baseline, and 1.19 and 1.98 doubling doses, respectively, compared with placebo. Van Rensen et $\mathrm{al}^{4}$ observed that a higher dose of FP $(1000 \mu \mathrm{g})$ for 4 weeks decreased BHR by 1.82 doubling doses compared with placebo, the effect being similar to that found in our study.

In a recent study in which 2 week intervals were used for testing the effect of a high dose of FP $(2000 \mu \mathrm{g})$ on BHR, the maximum reduction of 1.9 doubling doses of methacholine was achieved after 6 weeks of treatment. ${ }^{12}$ The maximum effect in the present study at 6 weeks was similar, but obtained with a much smaller dose.

Vathenen $e t ~ a l^{10}$ found a significant effect on BHR in adults with a single dose of $800 \mu \mathrm{g}$ budesonide after 6 hours, and Sherrington and Mallol $^{9}$ reported a significant effect in children with a single dose of $2000 \mu \mathrm{g}$ budesonide or $400 \mu \mathrm{g}$ fluticasone after 8 hours. The effect of the single dose disappeared after 12 hours. ${ }^{10}$ Recently, Gibson et al ${ }^{8}$ demonstrated a significant reduction in BHR to hypertonic saline in 6 hours with a large $(2400 \mu \mathrm{g})$ single dose of budesonide. In the present study the statistical method used (AUC) was not designed to look at the effect of a single dose; however, no decrease in BHR from baseline was found at 6 hours after $250 \mu \mathrm{g}$ FP. Taken together, previous data and those from the present study suggest that a higher dose of ICS can relieve BHR faster than a low dose.

The reversal of BHR after cessation of treatment might be dose dependent, but the evidence for this is scanty. Gershman et $^{11}$ found that, after a 6 week treatment period with FP, BHR reversed within 3 days when the daily dose was small ( $100 \mu \mathrm{g})$ but within 2 weeks after treatment with a higher dose $(1000 \mu \mathrm{g})$. We observed a significant reversal of BHR in 2 weeks after cessation of 6 weeks of treatment with FP $500 \mu \mathrm{g}$ daily; at that time BHR returned to near pretreatment levels.

A rapid reduction in BHR after starting ICS treatment is linked to a reduction in airway inflammation. A single dose of budesonide decreased bronchial responsiveness to hypertonic saline concomitantly with a reduction in sputum eosinophils but not in mast cells. ${ }^{8}$ Interestingly, a reduction in exhaled nitric oxide (NO) occurred with lower doses of ICS than the decrease in BHR to methacholine. ${ }^{3}$ Exhaled NO has been shown to be correlated with BHR in many studies of steroid naive asthmatics, ${ }^{12}$ reflecting the role of BHR as an indirect marker of airway inflammation. ICS reduce exhaled NO in a dose dependent manner, the effect starting within 3-5 days after onset of treatment. ${ }^{17}$ However, the time course of the effect of ICS on exhaled NO is not yet clear, and is not necessarily the same as that for BHR or other markers of inflammation.

Monitoring BHR during long term treatment for adjustment of corticosteroid dose in asthma has been clinically useful. When corticosteroid treatment was adapted by assessing BHR to methacholine, patients suffered about half the exacerbations observed in patients treated according to PEF measurements and symptoms only. ${ }^{18}$ Even a reduction in the thickness of the subepithelial reticular layer was found in bronchial biopsy specimens of patients whose treatment was guided by BHR measurements.

In the present study, simultaneously with the reduction in BHR, FEV increased slightly more in the FP than in the placebo group during the 6 week treatment period, but PEF values and symptom scores did not change during the last treatment week compared with those during the run in period. This may imply that PEF and symptom scores are less sensitive measures than BHR for assessing the treatment effect of ICS in asthmatic patients with only mild symptoms, 
as indicated by low symptom scores. By contrast, in patients with more severe persistent asthma, PEF and symptom scores have been shown to be good variables for assessing the effect of treatment. During treatment with FP, PEF and symptoms improved significantly within the first day and a sustained effect was attained in 2 weeks according to a recent metaanalysis. ${ }^{19}$

In conclusion, our results indicate that a daily dose of $500 \mu \mathrm{g}$ FP significantly reduces BHR to histamine by inducing a sustained effect within 3 days and a maximal effect within 6 weeks after the onset of treatment in patients with mild asthma. After cessation of FP treatment BHR seems to return to near pretreatment levels within 2 weeks. The findings suggest that BHR to histamine is a sensitive indicator of the effect of ICS and a valuable tool for adjustment of corticosteroid treatment in mild asthma. The findings further suggest that intermittent treatment periods of a few weeks' duration are insufficient to give long term control of BHR in patients with mild persistent asthma.

\section{ACKNOWLEDGEMENTS}

This study was supported by the Academy of Finland (research project 50656), Helsinki University Hospital (Research project TYH 2303), the Ida Montin Foundation, the Finnish Anti-Tuberculosis Association Foundation, and Glaxo Wellcome, Finland. The authors thank all the volunteers who participated, Professor Seppo Sarna for biostatistical advice, and $\mathrm{K}$ Ahlskog, E Repo and $\mathrm{M}$ Veneranta for nursing assistance.

\section{Authors' affiliations}

A R A Soviiärvi, H J Ekroos, A Saarinen, Department of Clinical Physiology, Helsinki University Central Hospital, Helsinki, Finland A Lindqvist, L A Laitinen, Research Unit of Pulmonary Medicine, Department of Medicine, Helsinki University Central Hospital

T Haahtela, Department of Allergy, Helsinki University Central Hospital

T Poussa, STAT Consulting, Tampere, Finland

\section{REFERENCES}

1 Dupont LJ, Rochette F, Demedts MG, et al. Exhaled nitric oxide correlates with airway hyperresponsiveness in steroid-naive patients with mild asthma. Am J Respir Crit Care Med 1998;157:894-8.

2 Jatakanon A, Lim S, Kharitonov SA, et al. Correlation between exhaled nitric oxide, sputum eosinophils, and methacholine responsiveness in patients with mild asthma. Thorax 1998;53:91-5.
3 Jatakanon A, Kharitonov S, Lim S, et al. Effect of differing doses of inhaled budesonide on markers of airway inflammation in patients with mild asthma. Thorax 1999;54:108-14

4 van Rensen EL, Straathof KC, Veselic-Charvat MA, et al. Effect of inhaled steroids on airway hyperresponsiveness, sputum eosinophils, and exhaled nitric oxide levels in patients with asthma. Thorax 1999;54:403-8.

5 Woodruff PG, Khashayar R, Lazarus SC, et al. Relationship between airway inflammation, hyperresponsiveness, and obstruction in asthma. J Allergy Clin Immunol 2001;108:753-8.

6 van Grunsven PM, van Schayck CP, Molema J et al. Effect of inhaled corticosteroids on bronchial responsiveness in patients with "corticosteroid naive" mild asthma: a meta-analysis. Thorax 1999:54:316-22.

7 Kraan J, Koeter GH, van der Mark TW, et al. Dosage and time effects of inhaled budesonide on bronchial hyperreactivity. Am Rev Respir Dis 1988; 137:44-8.

8 Gibson PG, Saltos N, Fakes K. Acute anti-inflammatory effects of inhaled budesonide in asthma: a randomized controlled trial. Am J Respir Crit Care Med 2001;163:32-6.

9 Sherrington CA, Mallol J. Early effects of inhaled steroids on airway hyperreactivity and pulmonary function in asthma. Pediatr Pulmonol 1999;27:376-82.

10 Vathenen AS, Knox AJ, Wisniewski A, et al. Time course of change in bronchial reactivity with an inhaled corticosteroid in asthma. Am Rev Respir Dis 1991:143:1317-21.

11 Gershman NH, Wong HH, Liu JT, et al. Low- and high-dose fluticasone propionate in asthma; effects during and after treatment. Eur Respir J 2000;15:11-8

12 Convery RP, Leitch DN, Bromly C, et al. Effect of inhaled fluticasone propionate on airway responsiveness in treatment-naive individuals: a lesser benefit in females. Eur Respir J 2000;15:19-24.

13 Quanjer PH, Lebowitz MD, Gregg I, et al. Peak expiratory flow: conclusions and recommendations of a Working Party of the European Respiratory Society. Eur Respir J Suppl 1997;24:2-8S.

14 Vilianen AA, Halttunen PK, Kreus KE, et al. Spirometric studies in non-smoking, healthy adults. Scand J Clin Lab Invest Suppl 1982;159:5-20.

15 Soviïärvi AR, Malmberg LP, Reinikainen K, et al. A rapid dosimetric method with controlled tidal breathing for histamine challenge. Repeatability and distribution of bronchial reactivity in a clinical material. Chest 1993; 104:164-70.

16 Crapo RO, Casaburi R, Coates AL, et al. Guidelines for methacholine and exercise challenge testing. Am J Respir Crit Care Med 2000;161:309-29.

17 Kharitonov SA, Yates DH, Barnes PJ. Inhaled glucocorticoids decrease nitric oxide in exhaled air of asthmatic patients. Am J Respir Crit Care Med 1996;153:454-7.

18 Sont JK, Willems LN, Bel EH, et al. Clinical control and histopathologic outcome of asthma when using airway hyperresponsiveness as an additional guide to long-term treatment. The AMPUL Study Group. Am J Respir Crit Care Med 1999;159:1043-51.

19 Szefler SJ, Boushey HA, Pearlman DS, et al. Time to onset of effect of fluticasone propionate in patients with asthma. J Allergy Clin Immunol 1999; 103:780-8

20 Nunn AJ, Gregg I. New regression equations for predicting peak expiratory flow in adults. BM 1989;298: 1068-70. 